\title{
The association of patient weight and dose of fosphenytoin, levetiracetam, and valproic acid with treatment success in status epilepticus
}

\author{
Abhishek G. Sathe ${ }^{1}$ (D) | Jordan J. Elm ${ }^{2} \quad$ James C. Cloyd ${ }^{1}$ (i) | James M. Chamberlain ${ }^{3}$ \\ Robert Silbergleit $^{4}$ (i) | Jaideep Kapur ${ }^{5,6}$ (i) \\ Nathan B. Fountain $^{8}$ (i) | Shlomo Shinnar ${ }^{9}$ \\ Robin A. Conwit $^{11}$ | Thomas P. Bleck ${ }^{12}$ (D) | Lisa D. Coles ${ }^{1}$ (D) \\ Hannah R. Cock $^{7}$ (D) । \\ | Daniel H. Lowenstein ${ }^{10}$ (I) | \\ ${ }^{1}$ Department of Experimental and Clinical Pharmacology and Center for Orphan Drug Research, College of Pharmacy, University of Minnesota, \\ Minneapolis, Minnesota \\ ${ }^{2}$ Department of Public Health Science, Medical University of South Carolina, Charleston, South Carolina \\ ${ }^{3}$ Division of Emergency Medicine, Department of Pediatrics and Emergency Medicine, School of Medicine and Health Sciences, Children's National \\ Hospital, George Washington University, Washington, District of Columbia \\ ${ }^{4}$ Department of Emergency Medicine, University of Michigan, Ann Arbor, Michigan \\ ${ }^{5}$ Department of Neurology, Brain Institute, University of Virginia, Charlottesville, Virginia \\ ${ }^{6}$ Department of Neuroscience, Brain Institute, University of Virginia, Charlottesville, Virginia \\ ${ }^{7}$ Clinical Neurosciences Academic Group, Institute of Molecular and Clinical Sciences, St George's University of London, London, UK \\ ${ }^{8}$ Department of Neurology, Comprehensive Epilepsy Program, University of Virginia, Charlottesville, Virginia \\ ${ }^{9}$ Montefiore Medical Center, Albert Einstein College of Medicine, Bronx, New York \\ ${ }^{10}$ Department of Neurology, University of California, San Francisco, San Francisco, California \\ ${ }^{11}$ National Institute of Neurological Disorders and Stroke, National Institutes of Health, Bethesda, Maryland \\ ${ }^{12}$ Feinberg School of Medicine, Northwestern University, Chicago, Illinois
}

\section{Correspondence}

Abhishek G. Sathe, Center for Orphan Drug Research/Experimental and Clinical Pharmacology, College of Pharmacy, University of Minnesota, Rm 4-226, McGuire Translational Research Facility, 2001 6th St SE, Minneapolis, MN 55455. Email: sathe134@umn.edu

\section{Funding information}

National Institute of Neurological Disorders and Stroke, Grant/Award Number: R01NS099653, U01NS056975, U01NS059041, U01NS088023 and U01NS088034; College of Pharmacy, University of Minnesota

\begin{abstract}
The Established Status Epilepticus Treatment Trial was a blinded, comparativeeffectiveness study of fosphenytoin, levetiracetam, and valproic acid in benzodiazepine-refractory status epilepticus. The primary outcome was clinical seizure cessation and increased responsiveness without additional anticonvulsant medications. Weight-based dosing was capped at $75 \mathrm{~kg}$. Hence, patients weighing $>75 \mathrm{~kg}$ received a lower $\mathrm{mg} / \mathrm{kg}$ dose. Logistic regression models were developed in 235 adults to determine the association of weight ( $\leq$ or $>75 \mathrm{~kg}$, $\leq$ or $>90 \mathrm{~kg}$ ), sex, treatment, and weight-normalized dose with the primary outcome and solely seizure cessation. The primary outcome was achieved in $45.1 \%$ and $42.5 \%$ of those $\leq 75 \mathrm{~kg}$ and $>75 \mathrm{~kg}$, respectively. Using univariate analyses, the likelihood of success for those $>75 \mathrm{~kg}$ (odds ratio $[\mathrm{OR}]=0.9,95 \%$ confidence interval $[\mathrm{CI}]=0.54-1.51$ ) or $>90 \mathrm{~kg}$ $(\mathrm{OR}=0.85,95 \% \mathrm{CI}=0.42-1.66)$ was not statistically different compared with those
\end{abstract}


$\leq 75 \mathrm{~kg}$ or $\leq 90 \mathrm{~kg}$, respectively. Similarly, other predictors were not significantly associated with primary outcome or clinical seizure cessation. Our findings suggest that doses, capped at $75 \mathrm{~kg}$, likely resulted in concentrations greater than those needed for outcome. Studies that include drug concentrations and heavier individuals are needed to confirm these findings.

\section{K E Y W O R D S}

antiseizure medications, dose-response, ESETT, seizure cessation, weight-based dosing

\section{1 | INTRODUCTION}

The Established Status Epilepticus Treatment Trial (ESETT), which completed enrollment in January 2019, was a multicenter, randomized, double-blind study to determine the best or worst second-line treatment among fosphenytoin (FOS), levetiracetam (LEV), and valproic acid (VPA) in patients with benzodiazepine-refractory status epilepticus (SE). ${ }^{1}$ The primary outcome of the study was cessation of SE at $60 \mathrm{~min}$ utes after the start of study drug infusion without use of additional antiseizure medication, as determined by absence of clinically apparent seizures and improved consciousness. Subjects aged $\geq 2$ years who failed first-line treatment with benzodiazepines and continued to have seizures were included in this study.

To maintain the blind, the three drugs, FOS, LEV, and VPA, had to be administered at the same volume and infusion rate even though the drugs had different $\mathrm{mg} / \mathrm{kg}$ doses. $^{2}$ The FOS product label recommends a maximum dose of FOS (prodrug of phenytoin) of $20 \mathrm{mg}$ phenytoin equivalents $(\mathrm{PE}) / \mathrm{kg}$ and that the rate of intravenous administration should not exceed $150 \mathrm{mg}$ PE per minute due to cardiovascular risks associated with rapid injection. ${ }^{3}$ Given that the ESETT protocol fixed the infusion time at $10 \mathrm{~min}$ utes, dosing was capped at $1500 \mathrm{mg}$ PE. As a result, all patients weighing $\geq 75 \mathrm{~kg}$ received the same capped dose of FOS $(20 \mathrm{mg} / \mathrm{kg}$, maximum $=1500 \mathrm{mg} \mathrm{PE})$. Similarly, weight-based dosing was also capped at $75 \mathrm{~kg}$ for LEV $(60 \mathrm{mg} / \mathrm{kg}$, maximum $=4500 \mathrm{mg})$ and VPA $(40 \mathrm{mg} / \mathrm{kg}$, maximum $=3000 \mathrm{mg}$ ).

Patients weighing $>75 \mathrm{~kg}$ received a lower $\mathrm{mg} / \mathrm{kg}$ dose; thus, lower drug exposure would be expected given the pharmacokinetic properties of these drugs. Therefore, we performed a secondary analysis to assess whether the odds of treatment success were lower in patients weighing $>75 \mathrm{~kg}$ as compared to those weighing $\leq 75 \mathrm{~kg}$. Because a primary outcome failure could be a result of one or more of the following: (1) need for an additional antiseizure medication before 60 minutes, (2) clinically apparent seizures at 60 minutes, and (3) lack of improvement in consciousness and response at 60 minutes, we also evaluated the association of weight and other predictors with clinical seizure cessation alone at 60 minutes.

\section{2 | MATERIALS AND METHODS}

ESETT was approved by institutional review boards for all participating institutions. ${ }^{1}$ Of the 478 patients enrolled in ESETT, $48.2 \%$ of adults and $0.9 \%$ of children weighed $>75 \mathrm{~kg}$. Because of the low number of children receiving a fixed dose and the possibility of differing response rates within children and adults, the analyses were limited to those $\geq 18$ years old $(n=249)$. Two patients were excluded because the study drug volume administered could not be determined. Among the 247 enrollments, 12 patients were enrolled more than once but only their first enrollments were used. Among the 235 unique adult patients, 132 (56.2\%) failed the ESETT primary outcome. Of the 132 failures, 87 (65.9\%) failed because they needed an additional antiseizure medication prior to 60 minutes, 10 (7.6\%) failed due to clinically apparent seizures at 60 minutes, and $35(26.5 \%)$ failed because they did not show an improvement in responsiveness at 60 minutes despite clinical seizure cessation.

\subsection{ESETT primary outcome as the dependent variable}

The ESETT primary outcome was expressed as binary ( $0=$ treatment failure, $1=$ treatment success $)$ and used as the dependent variable for the following logistic regression models.

\subsubsection{Association of weight with primary outcome using univariate and multivariate analyses}

Two logistic regression models were used to test the association of weight, as a binary predictor, with primary outcome using weight cutoffs of 75 and $90 \mathrm{~kg}$, respectively. A 90-kg 
cutoff was chosen to examine the association for higher weight individuals more rigorously. A logistic regression model also tested association of interactions of weight, sex, and treatment with the primary outcome. The model included treatment group (FOS, LEV, or VPA), sex (male or female), and weight as binary ( $\leq$ or $>75 \mathrm{~kg}$ ), with all the interaction terms (weight $\times$ treatment group $\times$ sex) as predictors of the primary outcome.

\subsection{2 | Association of weight-normalized dose and sex with primary outcome}

Separate logistic regression models were built for FOS, LEV, and VPA to test the association of weight-normalized dose in $\mathrm{mg} / \mathrm{kg}$ as a continuous variable, sex (male or female), and the interaction of dose and sex with the ESETT primary outcome.

\subsubsection{Association of weight, sex, and treatment with clinical seizure cessation without additional antiseizure medication}

A logistic regression model was used to test the association of weight and other predictors with clinical seizure cessation without additional antiseizure medication. Adult ESETT patients whose seizures were terminated but failed the primary outcome due to lack of improved responsiveness at $60 \mathrm{~min}$ utes $(n=35)$ were treated as successes. Clinical seizure cessation, as binary ( $1=$ success, $0=$ failure), was used as the dependent variable for this analysis. A logistic model with weight, as a binary ( $\leq$ or $>75 \mathrm{~kg}$ ), sex (male or female), and treatment group (FOS, LEV, or VPA) with all interactions (weight $\times$ treatment group $\times$ sex) as predictors was used to test their association with clinical seizure cessation.

Significance was determined as an alpha level $<.05$. All the analyses were conducted using R (v3.6.1), RStudio (v1.2.5001), and SAS (v9.4).

\section{3 | RESULTS}

\section{1 | Distribution of weights}

ESETT patients $\geq 18$ years old weighed from 36 to $157 \mathrm{~kg}$ and weights were approximately normally distributed, with a mean of $76.7 \mathrm{~kg}$ and standard deviation of $18.9 \mathrm{~kg}$ (Figure 1). Of the 235 patients, $113(48.1 \%)$ weighed $>75 \mathrm{~kg}$ and received the maximum doses. The overall success rate for the primary outcome was $45.1 \%$ in those $\leq 75 \mathrm{~kg}$ versus $42.5 \%$ in those $>75 \mathrm{~kg}$. Baseline characteristics of the adult population by weight group (Table S1) show that male patients were more likely to weigh $>75 \mathrm{~kg}(50 \%$ vs $66.4 \%)$, but all the other baseline characteristics were evenly distributed between the $\leq 75-\mathrm{kg}$ and $>75-\mathrm{kg}$ groups, respectively.

\section{2 | Comparison of response rates between the weight-based dosing group and fixed dose group}

The difference and $95 \%$ confidence interval (CI) in the response rates for those $\leq 75 \mathrm{~kg}$ versus those $>75 \mathrm{~kg}$ were $3.1 \%$ (95\% CI $=-20.5 \%$ to $26.6 \%)$ for $\mathrm{FOS},-1.2 \%(95 \%$ $\mathrm{CI}=-21.6 \%$ to $19.3 \%)$ for $\mathrm{LEV}$, and $6.4 \%(95 \% \mathrm{CI}=$ $-16.1 \%$ to $28.9 \%$ ) for VPA. None of the differences was statistically significant, as the $95 \%$ CI included 0 for each drug.

\subsection{Association of weight and other predictors with primary outcome using univariate and multivariate analyses}

\subsection{1 | Primary outcome versus weight}

The odds of success were $10.1 \%$ lower (odds ratio $=0.9,95 \%$ $\mathrm{CI}=0.54-1.51)$ for those $>75 \mathrm{~kg}$ compared to those $\leq 75 \mathrm{~kg}$ and $15.4 \%$ lower (odds ratio $=0.85,95 \% \mathrm{CI}=0.42-1.66$ )
F I G URE 1 Distribution of Established Status Epilepticus Treatment Trial (ESETT) adult patient weights and the response to the treatment administered as treatment success (blue) or treatment failure (red)

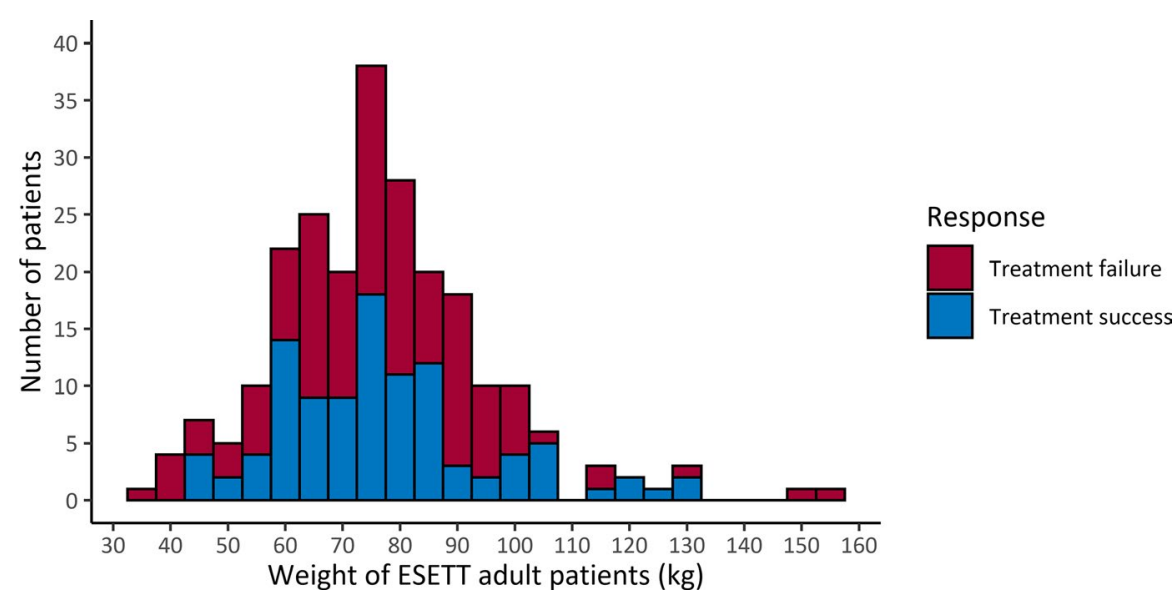


for those $>90 \mathrm{~kg}$ compared to those $\leq 90 \mathrm{~kg}$. These differences were not significant, as the $95 \%$ CIs for the odds ratios included 1 . Similarly, there was no statistically significant association with treatment success when sex, treatment group, and interaction of weight with sex and treatment group were included in the model (Table 1).

\subsection{2 | Primary outcome versus sex and weight-normalized dose}

When each drug was modeled separately, the weight-normalized dose was not associated with success, nor was sex or the interaction of dose and sex (Table S2).

\section{4 | Association of weight, sex, and treatment with clinical seizure cessation without additional antiseizure medication}

A total of 138 (59\%) patients did not have clinically apparent seizures at 60 minutes without receiving additional antiseizure medication (regardless of whether they were responsive to verbal commands or noxious stimuli). As seen from Table 1, weight ( $\leq$ or $>75 \mathrm{~kg}$ ), sex (male or female), treatment group (FOS, LEV, or VPA), and all the interaction terms (weight $\times$ sex $\times$ treatment group) did not have a significant association with clinical seizure cessation.

\section{4 | DISCUSSION}

The results of these secondary analyses demonstrate that the differences in response rates between the fixed dosing regimen $(>75 \mathrm{~kg})$ and weight-based regimen $(\leq 75 \mathrm{~kg})$ were not significant when the study drugs were grouped together or analyzed separately. The logistic regression models using the ESETT primary outcome and clinical seizure cessation without additional antiseizure medication as dependent variables also failed to find significant associations with weight, treatment, sex, or weight-normalized dose.

Fixed dosing, which is commonly used in adults, results in lower doses per body weight in heavier individuals and potentially lower drug concentrations for many drugs. Furthermore, if drug concentrations fall in the linear portion of the dose-response curve, lower drug concentrations may result in reduced efficacy. In this study, although approximately half of the ESETT adult patients received the maximum dose, the response rates between weight-based and fixed dosing regimen were similar. It is possible that weight or weight-normalized dose did not affect the primary outcome or clinical seizure cessation because the doses used in the trial resulted in drug concentrations greater than those needed for therapeutic outcome even in patients weighing $>75 \mathrm{~kg}$. Although this may be true, other predictors, such as drug concentration, would have been a better metric to evaluate the differences between responders and nonresponders. We know that drug concentrations can be variable in individuals receiving an identical dose. $^{4-6}$ There is also evidence that the pharmacokinetics of FOS, LEV, and VPA are altered in overweight and obese patients. ${ }^{7-10}$ In particular, patients with higher body fat will likely have greater volume of distribution. However, we were not able to investigate the effect of drug concentrations or body mass index (BMI), as sufficient information was not available. Furthermore, only 18 (7.7\%) patients weighed $>100 \mathrm{~kg}$. Thus, differences in pharmacokinetics, if any, may not have been large enough to impact the outcome.

The ESETT primary outcome was a composite and included absence of clinically apparent seizures and improved responsiveness at 60 minutes. It is possible that those who received higher doses were more likely to stop seizing but also more likely to have no improvement in responsiveness. To tease out the association of weight and other variables with clinical seizure cessation alone, we included those who failed the primary outcome only due to the lack of improved responsiveness at 60 minutes as successes, but found no significant differences between fixed and weight-based dosing. Future studies of SE will likely include electroencephalogram

TA B L E 1 Logistic regression models of the probability of success using weight, treatment, and sex with all interactions (weight $\leq 75 \mathrm{~kg}$ as reference group; $\mathrm{n}=235$ )

\begin{tabular}{lllll} 
Weight group & Treatment & Sex & $\begin{array}{l}\text { Using primary outcome as dependent } \\
\text { variable, aOR (95\% CI) }\end{array}$ & $\begin{array}{l}\text { Using clinical seizure cessation without } \\
\text { additional antiseizure medication as } \\
\text { dependent variable, aOR (95\% CI) }\end{array}$ \\
\hline$>75 \mathrm{~kg}$ & Fosphenytoin & Male & $0.71(0.20-2.55)$ & $0.56(0.14-2.26)$ \\
$>75 \mathrm{~kg}$ & Fosphenytoin & Female & $1.13(0.26-4.94)$ & $1.16(0.27-5.05)$ \\
$>75 \mathrm{~kg}$ & Levetiracetam & Male & $0.82(0.26-2.56)$ & $0.47(0.15-1.49)$ \\
\hline $75 \mathrm{~kg}$ & Levetiracetam & Female & $1.70(0.45-6.44)$ & $1.08(0.29-4.08)$ \\
$>75 \mathrm{~kg}$ & Valproic acid & Male & $0.83(0.26-2.66)$ & $0.72(0.22-2.40)$ \\
\hline $75 \mathrm{~kg}$ & Valproic acid & Female & $0.64(0.14-2.91)$ & $0.49(0.11-2.20)$ \\
\hline
\end{tabular}

aOR: Adjusted Odds Ratio 
as a part of outcome and allow us to better understand this subgroup.

A limitation of these analyses is the small number of patients in each treatment group ( 40/drug) weighing $>75 \mathrm{~kg}$. The wide CIs for the difference in response rates suggest that a larger sample size would be needed to confirm these findings. While these were secondary analyses, the adaptive study design was powered adequately for the primary outcomes.

\section{5 | CONCLUSION}

Weight-based dosing used in ESETT with a 75-kg cutoff does not appear to have an impact on the primary outcome or clinical seizure cessation. It is possible that the concentrations attained were greater than those needed for therapeutic outcome. However, studies with larger sample size and additional data (drug concentrations, BMI, etc) are required to confirm our findings. Future studies that measure drug concentrations would allow exploration of exposure-response instead of dose-response relationships.

\section{ACKNOWLEDGMENTS}

Research reported in this article was supported by the National Institutes of Health, National Institutes of Neurological Disorders and Stroke under awards U01NS088034, U01NS088023, U01NS056975, U01NS059041, and R01NS099653. Clinical trials.gov identifier is NCT01960075. A.G.S. was supported in part by the OLSTEINS Graduate Fellowship from the College of Pharmacy, University of Minnesota. We would like to acknowledge the ESETT Data and Safety Monitoring Board. The content of this article is solely the responsibility of the authors and does not necessarily represent the official views of the National Institute of Neurological Disorders and Stroke, National Institutes of Health, or the United States Government.

\section{CONFLICT OF INTEREST}

H.R.C. received consulting fees from BIAL Pharma UK and Sage Therapeutics; her institution has received funds for her work on other trials from UCB Pharma, Eisai Europe, Novartis, and GW Pharma. N.B.F. reports research grants awarded to the University of Virginia with N.B.F. as principal investigator from the Epilepsy Foundation, InSightech, UCB, SK Life Sciences, GW Pharmaceuticals, Neurelis, Takeda, Medtronic, and Cerebral Therapeutics. D.H.L. has served on the scientific advisory board of Bloom Science. J.C.C. received consulting fees from Neurelis Pharmaceuticals and reports funding awarded to University of Minnesota from Neurelis, holds a patent US9629797B2 on intravenous carbamazepine and intellectual property on intravenous topiramate, licensed to Ligand. The remaining authors have no conflicts of interest. We confirm that we have read the Journal's position on issues involved in ethical publication and affirm that this report is consistent with those guidelines.

\section{ORCID}

Abhishek G. Sathe (D) https://orcid.org/0000-0002-7348-4208 James C. Cloyd (iD https://orcid.org/0000-0002-3607-6619 Robert Silbergleit iD https://orcid.org/0000-0003-4101-2430 Jaideep Kapur (iD https://orcid.org/0000-0002-8608-1352 Hannah R. Cock iD https://orcid.org/0000-0002-5656-0141 Nathan B. Fountain iD https://orcid.org/0000-0003-2058-0308 Shlomo Shinnar iD https://orcid.org/0000-0001-6714-3960

Daniel H. Lowenstein (iD https://orcid. org/0000-0002-5869-4020

Thomas P. Bleck iD https://orcid.org/0000-0002-8267-9787

Lisa D. Coles (iD https://orcid.org/0000-0003-3613-9904

\section{REFERENCES}

1. Kapur J, Elm J, Chamberlain JM, et al. Randomized trial of three anticonvulsant medications for status epilepticus. N Engl J Med. 2019;381(22):2103-13.

2. Cock HR, Coles LD, Elm J, et al. Lessons from the established status epilepticus treatment trial. Epilepsy Behav. 2019;2019(101):106296

3. CEREBYX® (fosphenytoin sodium injection)[package insert]. New York, NY: Pfizer Injectables; 2015.

4. Tanaka J, Kasai H, Shimizu K, Shimasaki S, Kumagai Y. Population pharmacokinetics of phenytoin after intravenous administration of fosphenytoin sodium in pediatric patients, adult patients, and healthy volunteers. Eur J Clin Pharmacol. 2013;69(3):489-97.

5. Uges JWF, van Huizen MD, Engelsman J, et al. Safety and pharmacokinetics of intravenous levetiracetam infusion as add-on in status epilepticus. Epilepsia. 2009;50(3):415-21.

6. Park H-M, Kang S-S, Lee Y-B, et al. Population pharmacokinetics of intravenous valproic acid in Korean patients. J Clin Pharm Ther. 2002;27(6):419-25.

7. Clark SL, Leloux MR, Dierkhising RA, et al. IV fosphenytoin in obese patients. Neurol Clin Pract. 2017;7(1):45-52.

8. Abernethy DR, Greenblatt DJ. Phenytoin disposition in obesity: determination of loading dose. Arch Neurol. 1985;42(5):468-71.

9. Kuranari M, Chiba S, Ashikari Y, et al. Clearance of phenytoin and valproic acid is affected by a small body weight reduction in an epileptic obese patient: a case study. J Clin Pharm Ther. 1996;21(2):83-7.

10. Alzueta N, Ortega A, Aldaz A. Influence of sex, age, and weight on levetiracetam pharmacokinetics. Ther Drug Monit. 2018;40(5):628-34.

\section{SUPPORTING INFORMATION}

Additional supporting information may be found online in the Supporting Information section.

How to cite this article: Sathe AG, Elm JJ, Cloyd JC, et al. The association of patient weight and dose of fosphenytoin, levetiracetam, and valproic acid with treatment success in status epilepticus. Epilepsia. 2020;61:e66-e70. https://doi.org/10.1111/epi.16534 